\title{
Measuring Human Interaction in Digital Television Using Profiles and Geolocation
}

\author{
Valdecir Becker and Marcelo Knörich Zuffo \\ Laboratório de Sistemas Integráveis, \\ Departamento de Engenharia de Sistemas Eletrônicos, \\ Escola Politécnica da USP, \\ Av. Prof. Luciano Gualberto Trav. 3 n. 158, \\ 05508-900 SP São Paulo Brasil \\ valdecirbecker@usp.br, mkzuffo@lsi.usp.br
}

\begin{abstract}
This paper presents an audience measurement system for Brazilian digital free-to-air television, with profiles and geolocation introduction. The work uses activity theory framework for analyzing the context in which the audience and the interaction occur. There are nine user and behavior profiles proposed. The geographic distribution of the audience is shown by maps.
\end{abstract}

Keywords: Audience measurement, profiles, geolocation.

\section{Introduction}

This paper presents an audience measurement system for digital free-to-air TV using profiles and geolocation. Nine user and behavior profiles were developed from the activity theory analysis used in human-computer interaction for analyzing the context in which the interaction occurs, This allowed for a more detailed understanding of the viewers as compared with the traditional audience measurement. In addition, the system provides maps with the behavior and use in front of television. This information is useful in developing the content and precise advertising campaigns.

Traditionally, the audience measurement is based on tuned channels, generating data about time before television and most watched channels [1]. The measurement is done by companies like Ibope [2], in Brazil, and Nielsen [3], in United States, which connect audimeter on the receivers [11]. The audimeters get the tuned channel and send the information to a database. This process is limited in scope (total ratings, share, gross rating points and some profiles, such as age and social class) and causes discomfort to the viewer because of the need of an audimeter $[1,4,10]$. The audience measurement system reported in this paper eliminates the need for such audimeters.

\section{User Identification}

With the TV digitalization, one can use software that collects more detailed and precise data, without audimeter use [5,6]. The receiver [7] itself collects and sends 
data. In the system developed here, the receiver connects to a database, informing the current channel and the number of people watching television.

This article describes the evolution of the system, incorporating behavior and television use profiles in addition to the information related to user's location. For this purpose, the users at the measurement point are registered (Fig. 1). The definition about which households and user should be in the sample is obtained statistically, as typical audience measurement panels. For demonstration purpose, we defined five measurement points with 20 users, distributed among nine profiles, described below.

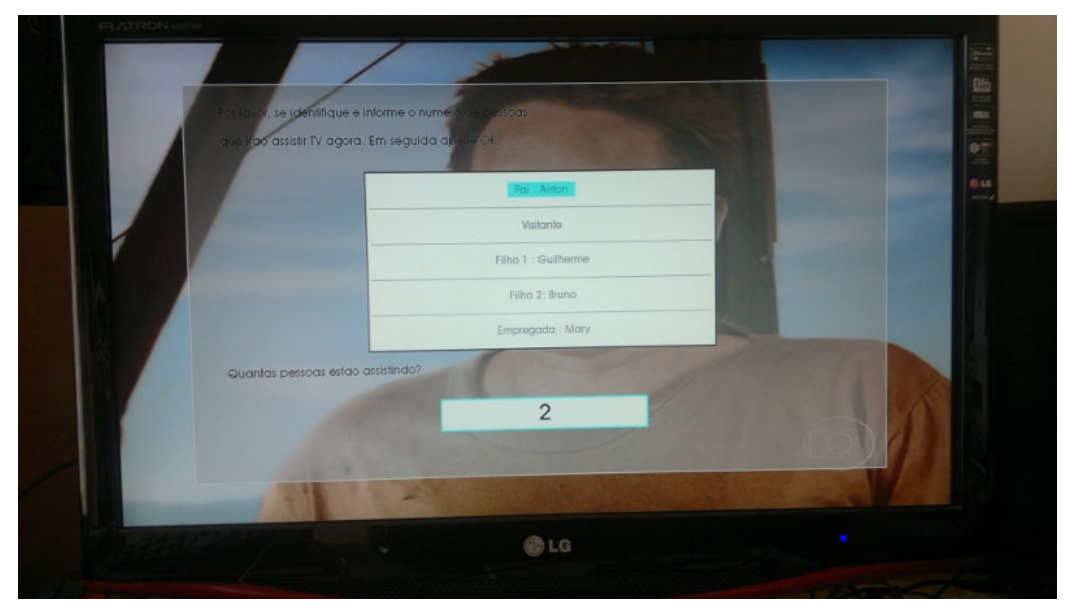

Fig. 1. Identification screen, which allows the association between the user and the profiles

When switched on, the receiver authenticates on the database using an IP connection, and receives information about the registered users. Then the user identifies itself. The receiver sends the information to the database with the location of it. The database does the association between identification and the profiles stored on it.

\section{Geolocation}

After the user identification, the receiver sends to a database the information with a Postcode number of the locality. The user registers the Postcode with the measurement software at the first time of turning on the TV with the measurement software. With this information, maps are prepared for the audience behavior, relating the location and with the profiles. The maps are generated using a methodology called Geofence [8], which designs a virtual perimeter with smaller maps in geographic areas pre-established by the Postcode number. Thus, it is possible to cross information between the user profiles and the audience, and locate them geographically. 


\section{Audience Profiles}

The profiles were defined based on activity theory, which is employed to interpret the use of technology and to develop systems for human computer interaction. Activity theory is mainly used in the activity-focused design, which starts the analysis not with the user, but with the activities required to complete the tasks. The analysis starts in the context of system use and the task actions, considering the activities involved in the process and the artifacts used in mediation [9].

This is the point where the activity theory becomes relevant to the development of user profiles and behavior with regard to television. The viewer uses technology (artifacts and tools) to establish a relationship with the content within a social context. Artifacts mediate this communication. From this context and such mediation, nine user and behavior profiles were defined, which can be analyzed individually or together.

1. Sex - male or female composition of the audience

2. Age - how old is the audience on the average

3. Disability profile - the need for accessibility

4. On line profile - internet access and frequency of use

5. TV audience profile - the average time watching TV

6. Commercial break profile - engagement in programming, change the channel during commercial breaks.

7. Crowd profile - how is the TV being watched, alone or accompanied.

8. Incoming profile - social class and average incoming

9. Technological profile - using technologies such as PC, cable TV, DVD player / Blu-ray / VCR, number of TVs

The profiles one, two and eight are already used by the measurement institutes, like Nielsen and Ibope. The profiles one, two, three, eight and nine are previously recorded with information provided by users. The profiles four to seven are updated monthly, based on the stored data.

These profiles can be applied to both fixed and mobile reception. The main difference between these two modes is the technology of collecting information, which should be transparent to those who access the information.

Besides the division into two lines of analysis, based on people who see TV (profiles 1-7) and the environment they occupy (profiles 8 and 9), one can also add profiles to the composition (profiles 1,2,3,8 and 9) or audience behavior ( profiles 4, 5, 6 and 7).

The information provided by the system can be accessed through an IP address. The user can select information by applying filters on the audience, share, on a particular profile or compose maps with profiles and behavior over the time. The intersection of information about audience and the different profiles allows detailed analysis about the composition and behavior of people watching TV. Fig 2 shows an example of the obtained data. 


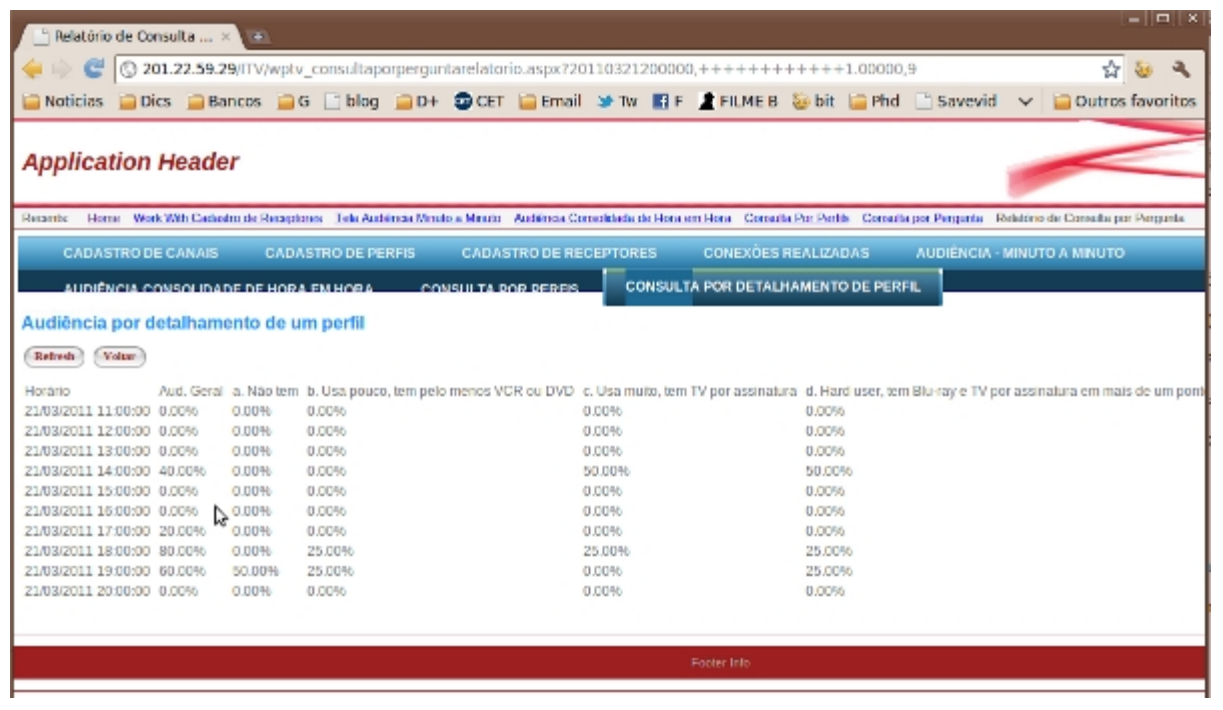

Fig. 2. Example screen with information about profile composition of the audience. In this case, with the Technological profile.

\section{Conclusion}

This work proposes significant reformulation of the way the audience is traditionally analyzed. Currently the most important audience information is only related to the time that the channel is tuned on and the number of people watching it. To this information we have added details of behavior and location, allowing the broadcasters to better plan the TV schedule and providing advertisers better investment targets. The combination of profiles and the geographic area allows us to understand the viewers' tastes and motivations. This understanding is essential to improving the television content.

\section{References}

1. Webster, J.G., Phalen, P.F., Lichty, L.W.: Rating Analysis: The Theory and Practice af Audience Research, 3rd edn. Lawrence Erlbaum Associates, Inc., Londres (2006)

2. IBOPE. Instituto Brasileiro de Opinião Pública e Estatística, São Paulo (2010), http: / /www. ibope.com. br (accessed 01/10/2010)

3. Nielsen: São Paulo (2010), http: / / en-us.nielsen. com (accessed 01/10/2010)

4. AIMC. El uso de la tecnología en la medición de las audiencias, Spain (2008)

5. Becker, V., Zuffo, M.: Audience measurement system for digital television. In: Adjunct Proceedings - EuroITV 2010, pp. 111-114. Tampere University of Technology, Tampere (2010)

6. Becker, V., Zuffo, M.: Medição de audiência em ambientes de TV digital. In: Proceedings of the XXXIII Congresso Brasileiro de Ciências da Comunicação. Caxias do Sul, RS (2010) 
7. Costa, L.C.P., Herrero, R.A., Nunes, R.P., De Biase, M.G., Zuffo, M.K.: Over the Air Download for Digital Television Receivers Upgrade. IEEE Transactions on Consumer Electronics 56(1) (2010)

8. Munson, J.P., Gupta, V.K.: Location-based notification as a general-purpose service. In: Proceedings of the 2nd International Workshop on Mobile Commerce, Atlanta, Georgia, USA, pp. 40-44 (September 28, 2002)

9. Kuutti, K.: Activity Theory as a potential framework for human-computer interaction research. In: Nardi, B. (ed.) Context and Consciousness: Activity Theory an Human Computer Interaction, pp. 14-44. MIT Press, Cambridge (1995)

10. Balnaves, M., O'Regan, T.: Survey wars: the explosion of measurement in audience ratings. In: Papandrea, F., Armstrong, M. (Org.) Record of the Communications Policy \& Research Forum 2009, Sydney, pp. 256-263 (2009)

11. Nielsen: Anytime Anywhere Media Measurement: A Progress Report, USA (June 14, 2007) 